\title{
Comportamiento económico reciente de El Salvador
}

Rafael Rodríguez Loucel

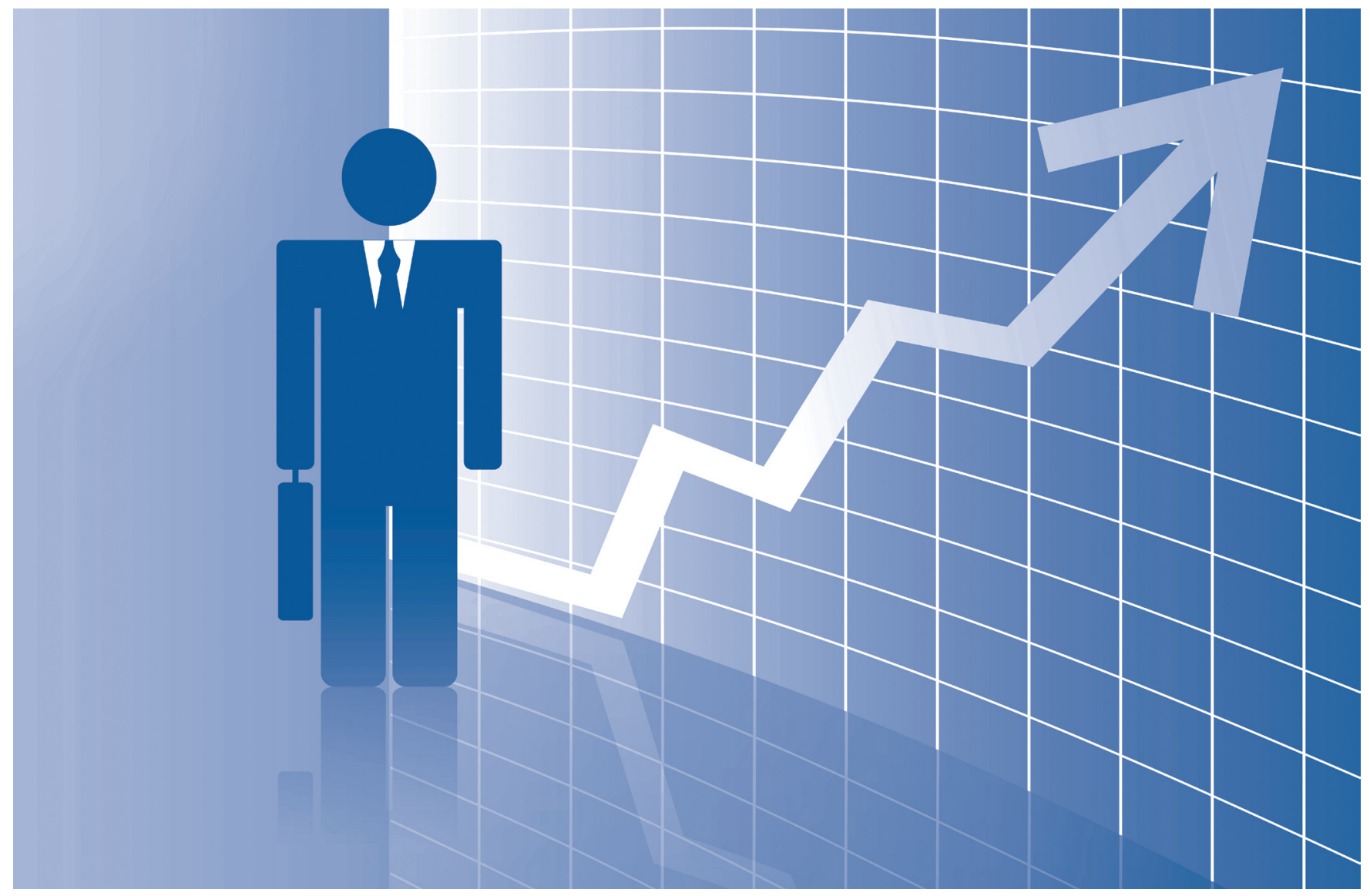

\section{RESUMEN}

La coyuntura no puede hacer abstracción del antecedente o de los aspectos estructurales que son determinante en el comportamiento económico presente; tampoco un fenómeno económico es aislado; necesariamente es vinculante con lo que acontece en lo político, social y ambiental. Por otra parte, la dependencia de la economía salvadoreña ha sido más obvia en los últimos veinte años, destacándose el ingreso de divisas en concepto de transferencias familiares del exterior y relativamente menos el proveniente de la venta de pro- 
ductos de bienes y servicios. Ese comportamiento es el resultado de una nula productividad y competitividad que no permite ampliar la base productiva y exportadora del país. Los patrones de consumo que no corresponden a los de un país con un nivel de producción bajo, pero si a un ingreso más alto que este último, son consecuentes con una sociedad con un porcentaje importante de sus habitantes que se acostumbran a las remesas y desatienden el nivel de preparación básica y su capacidad propia de asimilar y producir tecnología. La propensión promedio al ahorro y a invertir se han reducido, a lo que se agrega una poca atracción país para la inversión extranjera. Las autoridades gubernamentales tratan de resolver el dilema de captar más ingresos y/o promover la riqueza (capacidad productiva). Finalmente es urgente despolitizar el quehacer del país, que se mueven en un entorno de polarización política que obstaculiza las potencialidades de crecimiento natas, aún cuando no necesariamente efectivas del país.

\section{Antecedentes}

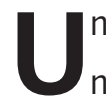
n análisis de la economía de un país en el contexto económico estricto tiene forzosamente que considerar aspectos relacionados con la estructura económica (variables reales), finanzas del gobierno, sector externo, deuda del país e indicadores financieros. Una vez examinado el comportamiento de los datos antes mencionados, se hace necesario buscar la relación causa-efecto, por cuanto el fenómeno económico no es aislado, siempre encuentra su explicación en sucesos internos y externos, así como en factores de índole social y política. Las ciencias sociales se entremezclan, lo que no permite el centrarnos en una ciencia única y autista los fenómenos sociales hay que analizarlos en un contexto de interdisciplinaridad.

La economía salvadoreña tiene sus particularidades que no le permiten tener un crecimiento sostenible, carece de fortalezas natas y presenta muchas debilidades de génesis. La ubicación geográfica de El Salvador se menciona muy frecuentemente como una fortaleza, la cual objetivamente hablando se vuelve relativa o su importancia se sobredimensiona. Una debilidad contundente a la que no le hemos prestado la debida atención es que la forma más expedita de estimular la innovación y el potencial de desarrollarse es la educación; hacer caso omiso por siempre de este axioma, esa es una "gran debilidad".

Esa identidad de típicamente dependientes y débiles, se pone de manifiesto en las situaciones de crisis mundial, al no contar con defensas propias que la protejan; los crecimientos del PIB históricos son casuales y generalmente están vinculados con impulsores externos (exportaciones, inversión externa, donaciones, remesas familiares), y dependen en alto grado de los ciclos económicos que experimentan principalmente la economía norteamericana. Estos incrementos esporádicos en el ingreso no tienen impacto positivo en la mayoría y se concentran en una minoría, por lo que el nivel de calidad de vida de un alto porcentaje de la población se mantiene en condiciones precarias debido a deformaciones identificadas con aspectos estructurales, como la desigual distribución del ingreso; las imperfecciones del sistema (institucional, político y social); el poco espacio y voluntad del poder económico para tomar decisiones de política macroeconómica acertadas oportunamente; la implantación con rapidez y con dispensa de trámites de medidas transcendentales que requieren de un consenso nacional, que afectan a toda la ciudadanía y que no tienen reversa por su alto costo de solo intentarlo. 


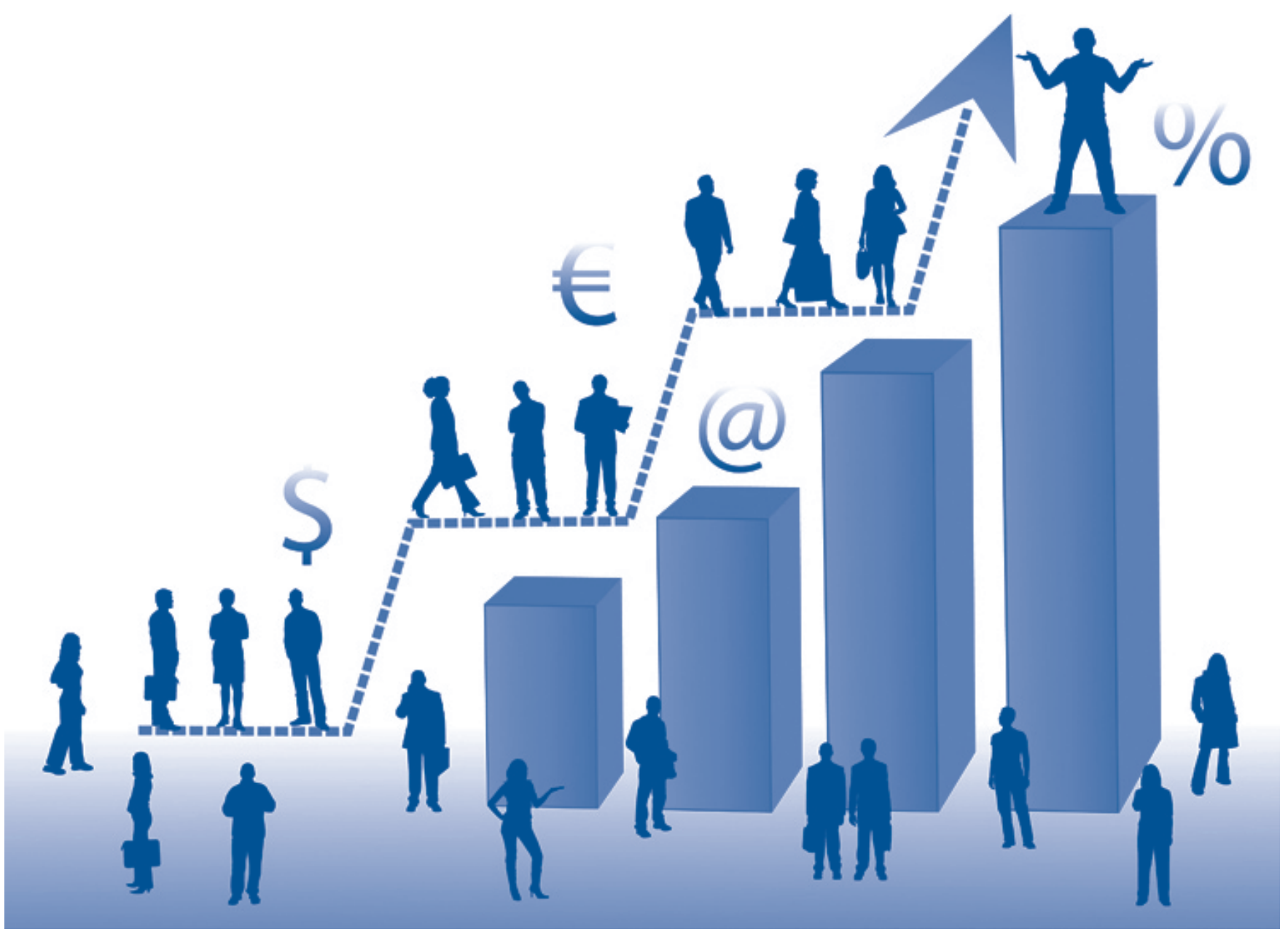

La poca prudencia en el endeudamiento antes de la crisis es otro proceder que nos indica que no ha existido nunca una voluntad de los tomadores de decisiones de solventar o enmendar la irregular conducción de la política macroeconómica por la predominancia de un esquema de intereses particulares que se sobrepone a los intereses colectivos, razón por la cual la mayoría de los ensayos de lectura de la actividad económica de El Salvador son de carácter coyuntural, superficiales y obedecen a patrones de corte internacional. (A continuación se realiza un breve análisis, tomando como base información preliminar de las fuentes al final citadas). Se pretende darle seguimiento al comportamiento económico del país (con informes periódicos y ensayos de encontrar las respuestas en el presente y el antecedente), a fin de mantener informadas a las autoridades de esta universidad, en primera instancia, y con el objetivo ulterior de tratar de influir en la opinión pública con un enfoque académico y realista.

\section{El ingreso y sus componentes}

La economía salvadoreña presenta un período de involución, muy lejos de un deseable crecimiento de una economía normal, incluso el comportamiento reciente del indicador tradicional de la actividad económica de un país, el Producto interno bruto (PIB), la sitúa en la de menor crecimiento de la región centroamericana, fenómeno contrario al antecedente histórico. En el año 2009 se registró un decrecimiento -3,3\%, comportamiento negativo record desde que se llevan registros de cuentas nacionales en el Banco Central de Reserva. El crecimiento de estas sigue siendo proyectado en $1 \%$ en 
2010 y en 2,5\% para 2011, ${ }^{1}$ las cuales tendrán que ser validadas en el futuro próximo. Ese resultado coincide con un coeficiente de ahorro y de inversión en relación con el PIB sumamente bajo, comparado con los registrados en la última década: 11,6\% y 13,2\%, respectivamente. Para el 2010 se estiman en $12,1 \%$ y $15,4 \%$. La economía tendió a cerrase, por cuanto las exportaciones e importaciones experimentaron decrecimientos considerables en términos porcentuales (y en volumen) $-16,5 \%$ y $-25,6 \%$ respectivamente, claros signos de impactos mayores en una economía débil de una recesión a escala mundial que ha afectado al mundo entero, pero con más fuerza a países como El Salvador, que no han podido concretar una planificación en términos de niveles altos de ahorro, inversión, producción y exportaciones (así como una diversificación de esas dos últimas variables). Para el 2010 se estima un retorno a incrementos de $17,8 \%$ y $17,8 \%$. La brecha comercial se amplió nuevamente, pero sin llegar a alcanzar los niveles del 2008. Financiera y marginalmente hablando, ese aislado hecho representa un menor daño, pero equivalente, al mismo tiempo, a una reducida recuperación de la actividad económica congruente con el alto grado de apertura de la economía.

En el 2009 también se registró una tasa negativa de inflación: 0,2\% (deflación). En el 2010 y 2011, se estimó una inflación de $2,1 \%$ y $3 \%$, respectivamente. El consumo -componente dinámico de la demanda que se ha mantenido a niveles considerables-, tanto el privado como el gubernamental, también experimentó una reducción. Se considera relevante destacar que en 15 años el nivel más alto de crecimiento del PIB ha sido de alrededor de 4\%; y en algunos años de ese período ni siquiera se ha alcanzado un crecimiento anual que rebase el crecimiento poblacional, característica de una economía con una pésima capacidad productiva, de ahorro e inversión por habitante en un coeficiente simple, lo cual se dramatiza con la inequidad en su distribución, circunstancia que facilita la incongruencia de que, a nivel nacional, persevere un ingreso y un gasto por encima de su producto nacional por el flujo de remesas familiares que envía la mano de obra laborando en el extranjero, que no pudo emplearse en el territorio nacional o que aspiró a niveles de calidad de vida inaccesibles en su país de origen, una incapacidad de generación de empleo cada vez más evidente, que amplía la pobreza y los índices de violencia en el país. Según información de Fusades cuya fuente original en materia de empleo es el ISSS, los niveles en 2010 todavía no recuperan los existentes en el período precrisis, indicador contundente para corroborar la incapacidad de un sistema para proveer de empleo a sus habitantes en edad económicamente activa.

El flujo permanente de divisas generalmente se ha traducido en la mayor importación de bienes de consumo duradero y no duradero, fenómeno que es observado con al menos dos ópticas: la primera, que ha contribuido al montaje de una economía relativamente sustentada en la dinamia de una intermediación de bienes y servicios importados en desmedro de otras actividades que, como la agricultura y la manufactura, experimentaron una actividad que en su momento se creyó pudiese asimilarse a un crecimiento incipiente de ambas actividades, con la perspectiva de ser estas actividades generadoras de mayor demanda interna y valor agregados, que los servicios que en la actualidad se abastecen principalmente de productos importados. Lo anterior da pautas para pensar en la posibilidad de una estrategia que fue concebida por los propietarios de las pocas cadenas de comercio, ante la inminente globalización y la falta de competitividad a escala internacional de productos agrícolas y de manufactura sencilla, como los que caracterizan a la experiencia productiva del país. Una segunda perspectiva (la del vaso medio lleno) es que ese flujo constante de remesas genera empleo interno y no genera inflación por tener una gran abertura, que es el crecimiento constante de las importaciones que evita la presión sobre la demanda interna. 
Una tercera óptica, menos analizada, precisamente porque trasciende el enfoque de coyuntura, es que ese flujo con entrada y salida, y que en el tiempo y en el espacio genera valor agregado concentrado en la intermediación de importaciones, nos distrae del esfuerzo de ser eficaces en la generación de productos primarios, secundarios y aspirar a incursionar en la aplicación de la tecnología en la rama de servicios. "Hace cien años pasamos de la agricultura a la manufactura, y la Gran Depresión (de 1930) es muchas veces vista como el punto de demarcación global. Y eso significa que los países realmente deben prepararse, tener los conocimientos y habilidades para competir en un mercado global" (Joseph Stiglitz ${ }^{1}$. Premio Nóbel de Economía). ¿Donde estamos? ¿Qué camino hemos recorrido? ¿Será que la prácticamente nula innovación en el país es sinónimo de una poca capacidad de concepción, gestación y ejecución de soluciones tecnológicas propias? Los interrogantes parecieran tener una respuesta en el tiempo y en los hechos.

Para 2010 y 2011 se han estimado y proyectado respectivamente, cifras que sugieren un efecto rebote de lo que pudo haber sido el toque de fondo de la crisis en El Salvador, en coincidencia con lo que aparentemente se especula en los Estados Unidos, país en el cual ya se habla de una recuperación, aunque todavía no lo suficiente fuerte para compensar el retraso experimentado. Por ejemplo, en la actividad inmobiliaria esa recuperación todavía no es tangible. En el caso específico de El Salvador las fuentes de cifras tradicionales, proyectan cifras de la inversión, el ahorro, las exportaciones y las importaciones, que se comparan con las experimentados con anterioridad a 2009. La recuperación global en forma más perceptible se observa en el impulso que se gestó en las exportaciones no tradicionales. En una concepción realista, esos niveles podrían considerarse como un retorno al comportamiento histórico, pero en ningún momento como una recuperación. La inflación, por su parte, sí retorna a niveles positivos para el 2010 y 2011 (2,1\% en ambos años), en consonancia con la inflación de los Estados Unidos y con las distorsiones de los precios relativos de la canasta básica en el país, generada en parte por el sistema de subsidios y también por la escasez de productos básicos de relativa importancia en la canasta básica. En vista de que la economía de El Salvador cada vez presenta incapacidad para generar impulsores de crecimiento internos y, por el contrario, tiene una mayor dependencia del crecimiento de las economías desarrolladas, principalmente la de Estados Unidos, esos niveles y su efecto neto positivo ulterior hacia el interior del país quedan supeditados, en primer orden, a lo que acontezca en ese país en el transcurso del año 2011, a la acertada conducción de la gestión gubernamental en el país y a la actitud del sector privado para mejorar su productividad empresarial y, con todo ello, no contrarrestar los aislados impulsos externos que eventualmente se suscitan.

Fusades en su Informe más reciente de coyuntura económica (octubre- diciembre 2010), consigna los siguientes mensajes: 1) La economía crece poco (impulsada por demanda externa y contraída por demanda interna). 2) La recuperación mundial avanza a buen ritmo, mientras El Salvador más lento. 3) El clima de inversión es negativo. 4) El empleo no se recupera.

Fusades asevera, en su último Informe trimestral basado en su encuesta "Dinámica empresarial", que los factores que más influyen en la percepción desfavorable del clima de inversión, por orden e importancia son: incertidumbre, delincuencia e inseguridad, falta de inversión y bajo nivel de actividad (por ejemplo, resultó más baja que Costa Rica, Guatemala y México). De lo que se deduce, y en el Informe citado se asevera en otro contexto, que para recuperar: el crecimiento, la demanda, el empleo y un favorable clima de negocios se requiere aminorar esos factores negativos y, además, lograr la sostenibilidad fiscal y aumentar la competitividad. Estos últimos aspectos se asemejan a los miembros de una 
ecuación en una relación de causa y efecto directa, y son los que, guardando su equivalencia, tienen que incrementarse a niveles mayores para generar una economía sana y de mayor productividad. Definitivamente, es "la alternativa" para el desarrollo de este país. Más productividad, más ingreso, más impuestos, más gasto social, más empleo, más estabilidad social.

\section{Finanzas del gobierno y política fiscal}

El Gobierno contribuye con acciones que contrarrestan, al gastar más de lo que percibe. 2009 es el año de referencia de este informe por ser las últimas cifras definitivas que poseen las fuentes tradicionales de generación y procesamiento de datos económicos en el país. Reflejan una relación de monto/PIB de $17 \%$ y $22,6 \%$ para los ingresos y gastos del gobierno central, habiéndose reducido $1 \%$ el ingreso y aumentado el nivel de gasto en menos del 1.0\%, mínimo, pero con tendencia contraria. También esos coeficientes relativos han experimentado una ligera alza en los últimos diez años, pudiendo afirmarse que en el ámbito del gobierno central nunca se ha observado un esfuerzo de austeridad en correspondencia con los niveles de ingreso. El balance corriente del sector público no financiero (ingresos corrientes-gastos corrientes) se ha vuelto estructuralmente deficitario, con el agravante de que recientemente el financiamiento externo ha servido para cubrir parte de ese desajuste, lo que para una empresa privada sería una especie de quiebra al no poder cubrir ni tan siquiera sus gastos de operación. En el sector público esos desajustes se pueden heredar a través de una mayor deuda. Consecuentemente, la deuda externa, tanto en término absolutos como relativos (en relación con el PIB) ha experimentado una tendencia creciente, a tal grado que desde el 2009 el porcentaje de la deuda en relación con el ingreso nacional rebasa el 50\%, y la proyección para 2011 de que se dispone la sitúa en $54,3 \%$.
La situación cada vez más precaria de las finanzas públicas adquiere dramatismo cuando se percibe el poco margen de maniobra, característico de las autoridades gubernamentales para implantar reformas fiscales con el principio de equidad como fundamento. El pacto fiscal se maneja no con criterio de consenso, sino de componendas, tratando de no afectar privilegios particulares añejos, por lo cual no redunda en incrementos sustanciales para manejar el quehacer económico con eficacia e interés colectivo. El efecto regresivo predomina sobre un sano y transparente efecto progresivo, y la ancestral cultura del engaño y del fraude se ha visto dimensionada recientemente por una falta de credibilidad en las autoridades, lo que en definitiva alimenta la evasión, elusión y el contrabando. Los organismos internacionales, principalmente el Fondo Monetario Internacional (FMI), consideran que la reforma de subsidios es clave, puesto que esta práctica ha sido mal conducida y ha representado una sangría de recursos públicos. El organismo internacional citado estima su coste en 1,4\% del PIB en 2009; el Gobierno se ha comprometido a reducir los subsidios al gas propano y a la electricidad y reorientar esos recursos al gasto social. El

How Long to Recover?

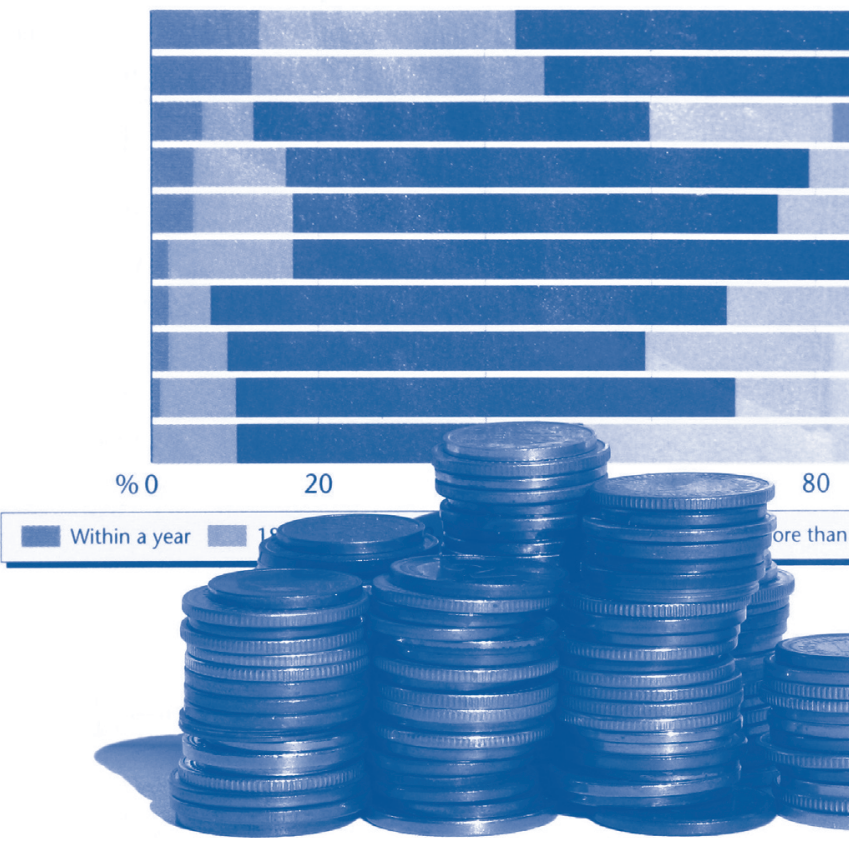


acuerdo de Stand By FMI-Goes plantea un ajuste de la carga tributaria del 2011-2015 de 3,1\% del PIB, o sea, de 0,62\% por año, cuando el dato histórico nos indica 0,21 a 5\% anual Eso significaría una triplicación anual de la carga en un contexto de débil crecimiento económico.

El control selectivo del gasto público, en vista de los obstáculos estructurales antes citados, hace difícil el cumplimiento de metas, como las que siempre impone el FMI en sus acuerdos de Stand by. También hay que considerar el programa de anticrisis que fue adoptado desde junio de 2009, que perseguía ayudar a mitigar los efectos de la recesión económica en los sectores más vulnerables de la población y preservarles un nivel mínimo de calidad de vida. El gasto total de este plan se estima que alcance los 575 millones de dólares, cerca del 1\% del PIB. Los pequeños incrementos en los ingresos, por otra parte, solo podrán esperarse por un esfuerzo continuado en la administración tributaría (mejoras en la auditoria y control de los grandes contribuyentes). Se aproximan tiempos de proselitismo, y las medidas económicas se archivan por su "costo político", lo que hará más difícil una conducta de disciplina fiscal, como la que requieren los acuerdos internacionales. El déficit de 2010 se ha financiado a través de la reducción de los depósitos del Gobierno, y en menor cuantía con la colocación de deuda en el mercado interno. El sector público no financiero se amplió y los gastos de seguridad, por lo consiguiente. El déficit fiscal de 2009 se estima que alcanzó 1.2 billones de dólares (5,4\% del PIB). Para el 2011, los funcionarios del FMI alentaron a las autoridades del Órgano Legislativo a aprovechar las condiciones del mercado para reorientar 650 millones de dólares de préstamos del Banco Mundial y del Banco Interamericano de Desarrollo, originalmente destinados para refinanciar el vencimiento de eurobonos. Con ello se cubre el déficit del 2009 y permite que el gobierno esté en capacidad de prestar hasta 1.1 billones de dólares. Con estos términos el Gobierno está habilitado para disponer de 300 millones de dólares de deuda con la banca doméstica (lo que le permite saldar pagos de 127 millones de dólares de una deuda de inicios del principio del año) y en noviembre emitir 800 millones de dòlares con un interés fijo a un plazo de diez años, y con ello recuperar su calificación financiera a escala internacional, en vista de que los eurobonos, que vencían a mediados del año pasado, estaban contratados en condiciones onerosas y significaban un effective yield de 7,375 \% a corto plazo. Se espera contar con la aprobación completa del programa de préstamos en breve. Cabe aclarar, según recientes indagaciones realizadas, que el nuevo arreglo con el FMI es un hecho, y los fondos de tres veces la cuota con ese organismo se tienen como fondos de contingencia que, de utilizarse, conllevaría un arreglo especial en que el Gobierno de este país tendría que someterse a implantar diversas medidas relacionadas con la política comercial y financiera. Un esquema similar existe en México.

La única salida para el país es el trabajo de una sociedad dispuesta a trabajar en consenso y, por primera vez, despolitizada y con intereses colectivos definidos y trasparentes En todo caso, el Gobierno tiene que emplearse a fondo para la implantación de nuevas medidas en un escenario que presenta mucho riesgo político. Si el financiamiento externo no pudiese materializarse, porque no lograse el soporte necesario que se requiere de la Asamblea Legislativa para adicionales reformas, el gasto deberá ser irremediablemente reducido para evitar el incumplimiento de compromisos financieros a corto plazo en el mercado doméstico.

\section{SECTOR EXTERNO Y DEUDA}

El déficit en cuenta corriente externo crónico se redujo en 2009, aun cuando se prevén leves incrementos para 2011 y 2012. El saldo de la deuda del sector público en relación con el PIB, ya mencionada, es preocupante: $52,2 \%$ en 2009 , con posibilidad de llegar a 55,0\% en 2011, en un escenario pesimista, y reducirse hasta $51,5 \%$ en un escenario optimista, lo que se constituye en uno de los principales obstáculos para 
las posibilidades de crecimiento del país. La deuda externa con respecto a la deuda total del país fue de 60,5 \% para 2009, y su importancia en la estructura de la deuda total se estima que persistirá en los siguientes dos años. La inversión extranjera directa en relación con el PIB se ha reducido 2,7\% en comparación 6,9\%.

\section{Aspectos monetarios vulnerabilidad externa e indicadores de liquidez}

Entre los aspectos de mayor relevancia de este apartado, además de que se mantiene la dolarización, se encuentra la menor dinámica que presenta la oferta monetaria M2 circulante y cheques de solo 1,2\% anual. En igual forma, Ilama la atención la reducción en el porcentaje del crédito doméstico en relación con el PIB: 46,85\% en el 2009, el más bajo que registra las cifras disponibles desde el año 2000 (ver anexo). La baja del crecimiento de la liquidez en el país en los últimos años es impresionante, y no por lo que reflejan las cifras a escala macroeconómica, sino por lo que personalmente se escucha del empresario en todo ámbito, principalmente del pequeño y mediano, de sus dificultades de obtener crédito de la banca actual de propiedad extranjera. La relación crédito domestico con respecto al PIB fue de $46,8 \%$ en 2009 , en comparación con 52,8\% que registró 2010. En el pasado más lejano, ese coeficiente debió de haber sido mayor. El ratio de liquidez actual es de aproximadamente 70.0, comparado con 114.6 que registró el año 2000. El indicador de vulnerabilidad externa medido por deuda externa de corto plazo, más el período de vencimiento de la deuda externa de largo plazo, más los depósitos de los no residentes por encima de un año de vencimiento; todo con respecto al saldo de reservas internacionales (se entiende, en poder del BCR) presenta una tendencia hacia la baja desde 2005 en que se registró el coeficiente más alto 167.0. Este indicador de vulnerabilidad externa es estrictamente financiero y difiere del que se conoce en el área comercial.

\section{Prospectiva país}

Más allá de los problemas del momento, denominados por la inmensa mayoría como coyunturales, se encuentran los

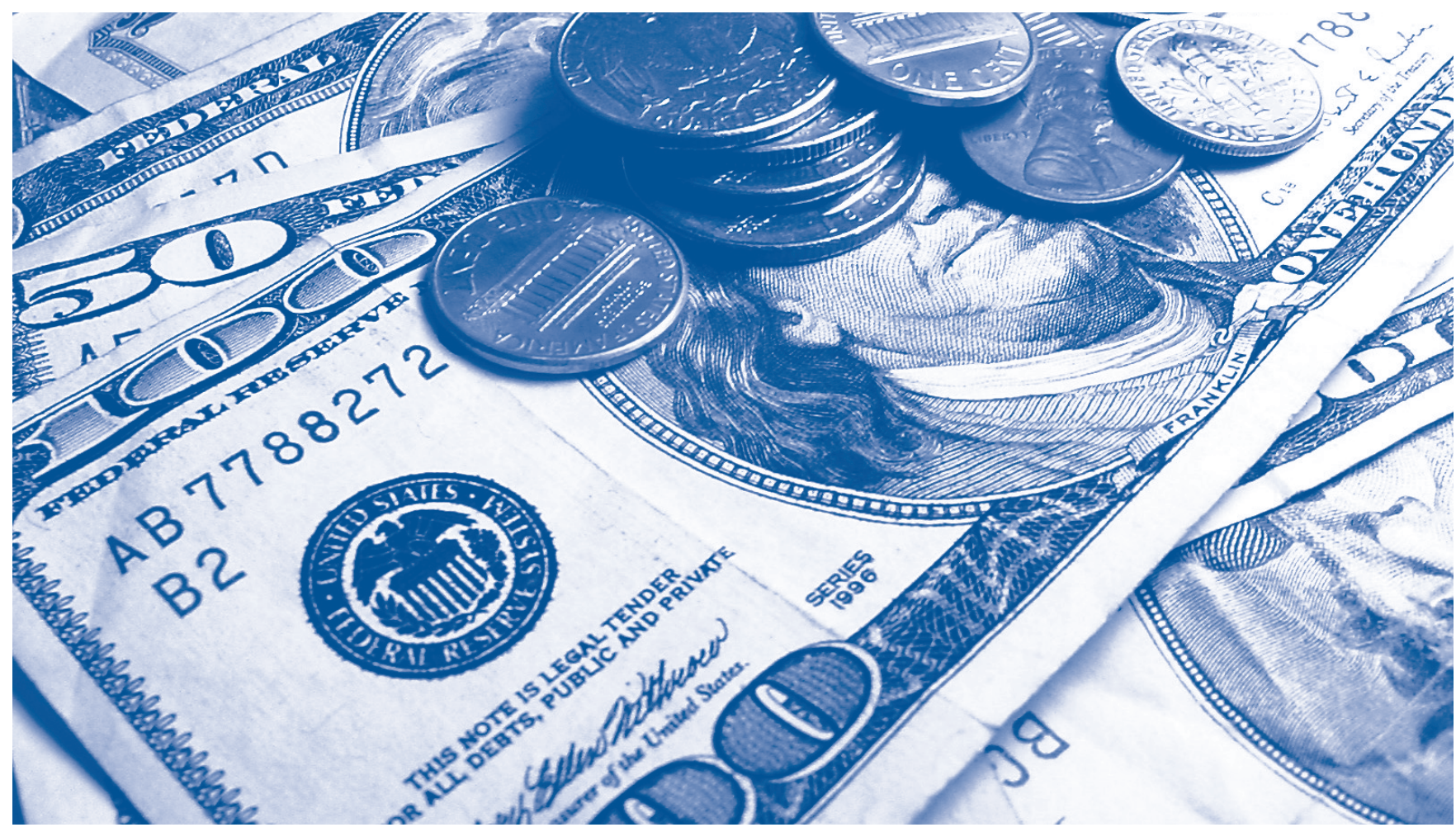


problemas estructurales del país y de toda su existencia como nación. Un acuerdo con el FMI ayuda a la austeridad, pero limita la libertad de acción. Son patrones que se pretende adaptarlos a todos los países que optan por préstamos de contingencia y acuerdos de Stand by. El mayor grado de cumplimiento de metas (referidas generalmente a límites de déficit fiscal y endeudamiento externo público y privado) son necesarios para un gobierno que desea implementar reformas impositivas sin perder popularidad, escudándose en que existen acuerdos internacionales que respetar, pero limitan el crecimiento cuando la supervisión de los límites de crédito entorpece la dinamia productiva de un país. Cuando un país como El Salvador pasa por una situación de estancamiento, de falta de credibilidad gubernamental, límites de endeudamiento rebasados y opciones de crecimiento prácticamente nulas, y desea concretar un pacto fiscal; un acuerdo con el FMI (con condiciones financieras extremas, seguramente) se plantea como salida, y su cumplimiento se vuelve estratégico para acceder a préstamos de mayor plazo de otros organismos internacionales, como son el BID y el BM. El programa de soporte de tres años con el FMI es el tiempo justo y necesario para que el país tenga la oportunidad de recuperarse de los efectos de la crisis, que han sido más profundos y dilatados en El Salvador que en otros países vecinos, que estaban productiva y financieramente preparados. Tres años también son el tiempo suficiente para respaldar el pacto fiscal y la reforma fiscal que ello conlleva, y así sentar las pautas del programa social ambicioso que el Gobierno actual quiere implantar. Incluso el programa, como un todo, serviría para que la comunidad financiera se constituya en un catalizador de la capacidad del país en el manejo de un programa financiero integral.

Cuando la situación es crítica, -como es el caso de El Salvador-, el poder de negociación es bastante limitado y está expuesto a una "condicionalidad dura" que atenta contra su in- dependencia de gobernar. El FMI ha sido bastante criticado y ha cargado con la culpabilidad de los desajustes financieros profundos (chivo expiatorio) de varios países. Sin embargo, el beneficio de la duda persiste, sobre todo para países que se caracterizan por una polarización política extrema, que no da cabida al consenso requerido para implantar políticas que se vuelven oportunas y necesarias. Un ejemplo es la reforma fiscal, en la cual el FMI solo fija metas (cuotas, saldos, límites), pero no se inmiscuye en la calidad del ajuste; y es aquí donde un gobierno no comprometido debe de aprovechar para establecer una política fiscal que, además de lograr la austeridad, permita cumplir por primera vez con el principio de equidad, objetivo por excelencia de esa política.

El gobierno actual tiene la oportunidad de un nuevo arreglo con el FMl y de negociar un nuevo programa de soporte con el FMI (en febrero de 2009 se realizó un acuerdo). Un nuevo acuerdo podría ser un arreglo de tres años para fundamentar una confiabilidad en la preservación de una estabilidad macroeconómica. Se ha tenido acceso al reporte del año pasado del staff del FMI, en el cual se proponía un nivel de acceso de 300\% de cuota (SDR 513.9 millones), con un seguimiento de revisiones semestrales. Existen consideraciones de orden técnico de mucho fondo que ameritan un análisis exhaustivo, y personalmente considero que muchas de ellas le darían fortaleza a un pacto fiscal y a una política financiera adecuada, considerando los tiempos difíciles que atraviesa el país; pero son las autoridades políticas las que tomarán las decisiones en las cuales el costo político prevalecerá.

\section{1/ REFERENCIAS}

Reportes del Banco Central y página web de esa misma entidad. Informes de coyuntura económica de Fusades

- Fuentes disponibles de datos: Misión del Fondo Monetario Internacional y Moody's Statistical Handbook Country Credit. Noviembre de 2010.

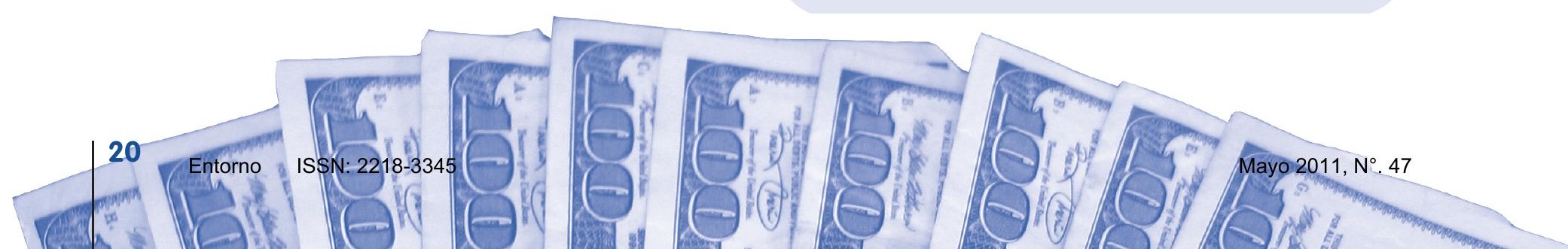

